\title{
Comentário I
}

Eduardo Diatahy Bezerra de Menezes

Universidade Federal do Ceará

Instituto Histórico do Ceará

"Virou peça de museu!" Eis uma expressão usual para designar algo pessoa, instituição ou objeto - que se tornou obsoleto, superado. Todavia, para quem acompanha o fogo cruzado das críticas sobre os museus, que já duram mais de três décadas, ela não faz mais do que exprimir na pragmáica quotidiana aquilo que os analistas discutem em seus estudos. É no esforço de inovar essa vertente de reflexões que se apresenta este ensaio denso, amplo e consistente, de Ulpiano T.Bezerra de Meneses. Como tal, tende a suscitar no leitor crítico reações diversas. Pessoalmente, sinto-me inclinado a um acordo geral no atacado, embora incitado a tecer comentários nos retalhos. Aqui, o risco mais imediato reside na possibilidade de escorregar para os reparos abundantes e multifários. Outra tentação de quem faz a apreciação está em querer apontar as lacunas e os silêncios do autor, iá que a problemática examinada está prenhe de questões correlatas ou afins. No entanto, o próprio autor expôs honestamente os limites do quadro em que situa as indagações de seu discurso crítico. Assim, para guardar a regra da parcimônia, evitando os riscos apontados, limitar-me-ei a alguns pontos que me tocaram mais intensamente. Seguirei, pois, a rota dos pormenores.

Embora, ao longo do texto, o autor haja distribuído preciosas e argutas observações epistemológicas sobre a produção do conhecimento em geral e do conhecimento histórico em particular, cujo alcance e cujo valor alcançam amplo horizonte, não me parece justo deixar sem assinalar sua posição face a essa gnosiologia de senso comum, enraizada na tradição aristotélica e tomista, segundo a qual "o sensivel é o veículo natural do intelegivel" (p.9)., conforme menciona a partir do trabalho de Hooper- 
1. Embora secundária, gostaria de levantar uma questão paralela às discussões contidas em todo o texto e mais especialmente nesta terceira parte: por que não utilizar o qualificativo museal, como o faz a língua francesa, já que $m u$ seológico (usado com frequiência e de forma inadequada pela maioria dos autores) refere-se a museologia e, não, a museu?
Greenhill (1988). A despeito de o aforismo de Goethe, no Fausto, sustentar que "no princípio está a ação" e apesar da ampla crítica exercida contra ela pela Epistemologia contemporânea, essa insidiosa "idéia recebida" perdura no fundo de nossas consciências como uma conquista inexpugnável /ver a propósito o belo artigo de Piaget 1970 .

Seguindo ainda essa ordem de considerações que abrem o texto, penso que o termo teatro, posto comporte a significação de sua apontada etimologia grega, penso que mesmo no caso em tela ele possui maior riqueza semântica na medida em que remete para a noção de encenação e espetacularização. Idéia que ficará mais explicitada na ulterior vertente do living museum, que aliás o autor examina criticamente na terceira parte de seu texto. Mas aqui penso igualmente, para ilustrar meu comentário, num autor como Bacon, contemporâneo desse uso do termo, quando arrola, entre os elementos perturbadores do pensamento humano acerca da realidade, os idola theatri, onde o vocábulo não se refere ao olhar, ao ver, mas antes às representações e opiniões herdadas da tradição (filosofias, concepções, fábulas, ficções, etc.).

Mas entremos de plano no corpo do argumento. $O$ autor divide o seu texto em quatro partes. Na primeira - $O$ Teatro da Memória -, ele retraça os limites da problemática que vai enfrentar, distingue a visão tradicional de um museu histórico (que constifui objeto preferencial de suas reflexões) e suas funções da visão crítica e atualizada, que examinará mediante dois questionamentos fundamentais: "que possibilidades pode haver de participação do museu histórico na produção do conhecimento histórico?" e "como, nessa perspectiva, funciona a exposição museológica?". Antes de desenvolver essa discussão central que irá ocupar as duas partes finais do texto, ele antecipa seus pontos de partida numa segunda parte - Premissas -, onde elabora, com razoável extensão, sua concepção teórico-analítica, se assim me posso exprimir, para articular criticamente as categorias básicas com que se defronta a museologia hoje: "museu e acervo", "tipologia de museus e o museu histórico", "objeto histórico / documento histórico", etc. 'Segue-se a terceira parte - A exposição histórica -, a mais longa, que discute as várias vertentes das práticas e interpretações dessa função tradicional dos museus históricos. E, finalmente, a quarta parte - História e museu histórico: o Laboratório da História -, que contém, no meu entender, a principal originalidade deste ensaio cuja generosa sugestão foi sendo gestada nos tópicos que a antecederam, daí o seu caráer mais conclusivo e prospectivo.

Antes de prosseguir com outros comentários acerca do texto, acredito ser importante tomar posição sobre questões preliminares ou que subjazem à existência e ao estauto de museus. Refiro-me à questão da preservação do patrimônio cultural e à da memória coletiva (de que a História pretende ser a formulação científica). Há um sem número de problemas implicados aí. Serei breve e seletivo.

Posto que positivamente relevante, a consciência preservacionista, que parece ser um dos traços dominantes da humanidade deste final de milênio, é, como toda ação humana, sinuosa e contraditória, por isso não deixa de possuir seus aspetos nefastos. Imaginemos se fosse possivel a existência de tal mentalidade na época dos tiranossáurios e outros monstros pré-históricos! 
Provavelmente, a espécie humana ainda não teria surgido no cenário zoológico do planela e, muito menos, estaria eu aqui a fazer semelhantes lucubrações. Portanto, se tomarmos o sentido etimológico do termo, ou seja, a noção de sofrimento, de moléstia provocada pela recordação de experiências passadas, parece legítimo admitir que essa discussão tem seu quê de nostálgico, de páthos, no sentido de um viés da percepção, em decorrência do desejo de regressar a situações anteriores, que as mutações históricas recentes tansformaram profundamente. Não estou a defender aqui uma posição novidadeira segundo a qual toda mudança sociocultural seria necessariamente boa ou que todo regresso seria, por igual, molesto. Não pretendo entrar nesse escorregadio território dos juízos de valor. Apenas creio constatar modificações mais ou menos ireversíveis e progressivamente superáveis em relação às tradicionais formas institucionais de registro da memória coletiva e de preservação do patrimônio histórico e cultural. ${ }^{2}$

Se no limite todos os museus são históricos e se a história é tálvez um dos interesses mais arraigados do homem, ente que se institui e se funda na memória e na narratividade, por que não preservar tudo? Já que isso seria impossivel, pois acarretaria em fixar a história cuja dinâmica exige dialética de criação e extinção, nesse domínio, portanto, a indagação crucial é: que coisas preservar e por quê? Ora, o segundo membro do questionamento é de resposta relativamente mais fácil. Na escala zoológica, a espécie humana parece ser a única movida pela perpétua aspiração a fazer melhor tudo aquilo que possa tornar-se mais belo, mais perfeito e mais duradouro; ela parece habitada pelo desejo de perfeição que tende ao absoluto. No que tange, por exemplo, às cidades - lugar por excelência do tipo de memória e modalidades de registro a que estamos nos referindo nesta discussão -, é mediante elementos arquitetônicos, equipamentos e artefatos, e por meio das formas concretas de organização espacial da vida coletiva que o homem estrutura as marcas de sua memória, assegurando o caráter social de sua experiência histórica. Mas aí reside também a enorme dificuldade da resposta ao primeiro membro da indagação: que coisas preservar? Que processos de construção social do sentido e que dispositivos de seleção e excludência fazem com que, da infinita multiplicidade de objełos, uns se tornem lixo e sejam destinados ao extermínio e à rejeição, enquanto outros se transformam em objetos históricos ou obras de arte merecedores de espaços privilegiados nos santuários da cultura e motivos de intensa veneração?

Grosso modo, posso afirmar que o poder constitui um dos eixos principais à volta do qual se estrutura a memória coletiva. $O$ outro é a morte, que estabelece uma finitude a ser superada pela consciência de nossa temporalidade e pela lembrança. Obviamente, existem na elaboração de nossos registros outros componentes de relevo, dos quais o mais importante é por certo o sagrado. Mas considerarei aqui apenas o primeiro elemento, que é básico para o meu comentário. Eis por que Jacques le Goff nos adverte para a importância da memória coletiva na luta das forças sociais pela dominação do corpo social; desse modo, assegurar a posição de senhores da memória e do esquecimento tem sido uma das grandes preocupações das classes, dos grupos, dos indivíduos que dominaram e dominam as formações sociais; e os
2. Só para assinalar a existência de vários outros problemas aí implicados, menciono o caso do Egito, cujo território quase todo é uma espécie de extenso museu, sempre às voltas com a carência de recursos financeiros e técnicos para preservar seu acervo descomunal. O país vê-se obrigado a enfrentar questões de soberania e de revivescência de vínculos coloniais ao aceitar a ajuda de outros países mais ricos. Para não falar no fato de uma de suas principais fontes de reservas estrangeiras ser a indústria do turismo internacional que tem provocado a expansão urbana nos locais dos sítios arqueológicos, acarretando enormes danos a seus monumentos em virtude de várias formas de poluição e destruição. 
esquecimentos, os silêncios da história são reveladores desses dispositivos de manipulação da memória coletiva (1988: 109).

Ora, numa ordem social como a nossa, extremamente hierarquizada e expondo diferenças abissais de situações de vida, é fácil supor como são discriminatórios os mecanismos de seleção, de consagração e de preservação. Numa ordem social desse gênero, talvez a única coisa efetivamente igualitária seja algo como a SIDA (Aids), que incide diferentemente em todas as classes, sem opção preferencial evidente. O mesmo não se dá com a preservação da memória e do patrimônio, que essa é amplamente elitista. Com efeito, nas sociedades arcaicas ou nas massas espoliadas das sociedades modernas, à margem das tecnologias da escrita e correlatas, a memória é assegurada particularmente pelos recursos narrativos orais (lendas, mitos, contos, epopéias etc.) e por alguns poucos artefatos e marcas iconográficas. Essas significativas parcelas da humanidade não costumam deixar ou deixam raros registros arquitetônicos e urbanos, e mais raros monumentos. A cidade é fenômeno recente na história e o que fica de sua memória é privilégio das classes dominantes. As camadas desfavorecidas, que constituem no entanto as mãos que as construíram, possuem, na melhor das hipóteses, a possibilidade de sua eventual fruição estética, já que, como símbolos do poder, não se costumam velar monumentos e fachadas de palácios, do mesmo modo que a praça pública e a lua se expõem generosamente.

Postas esssas considerações, retomo agora mais especificamente o comentário do ensaio.

No calor das discussões sobre museus, essas instituições foram qualificadas de túmulos, mausoléus, necrópoles, necrotérios da cultura, etc., e têm sido alvo de críticas ferozes. O autor repassa a maioria das questões que têm alimentado esse debate, como a que sugere sejam os museus transformados de "templos" em "fóruns". Na verdade, mais do que templos, pois até os nossos positivistas construíram o seu no Rio de Janeiro. Não me parece gratuita a tendência a conceber os museus como santuários - edifícios monumentais recheados de tesouros do passado como as criptas das velhas catedrais e basílicas -, já que costumam ser produtores de uma espécie de hagiografia heroificante e se constituírem em locus onde se realiza o culto patrimonial e onde melhor se materializa a metáfora conservadora expressa na idéia de altar da pátria.

Na seqüência dessa discussão, o autor evoca uma questão reiterada entre nós: é possível museu sem acervo? Não pretendo entrar nessa discussão e considero pouco feliz a analogia da "mula sem cabeça" que ele utiliza para criticar o argumento dos que defendem a proposição contida na questão. Como quer que seja, parece legítimo pensar em acervo sem museu...ou na sua banalização pelos recursos de multimeios postos atualmene à nossa disposição.

Mais adiante, o autor se opõe à idéia de acervo sem museu, pois, na sua opinião, a inteligibilidade do mundo material sofreria rude golpe em qualquer sociedade complexa, na medida em que o desenvolvimento das técnicas desse campo não reduziria a função do museu em matéria de documentação. Posto não concorde inteiramente com ele, sou obrigado a reconhecer a elegância idealística de seu argumento: "[o museu] continuará a justificar sua existência pela necessidade de dar conta da apreensão sensorial, 
empírica, corporal, exigida pelo universo da cultura material (sem esquecer implicações sociais, como as da 'aura' ou da fetichização - de que os museus são os instrumentos ideais, não de cultivo, é claro, mas de análise). Além disso, no museu, a dimensão cognitiva sempre se imbrica, profundamente, na afetiva. Estou convicto de que, no século XXI, os museus não serão espaços anacrônicos e nostálgicos, receosos de se contaminarem com os vírus da sociedade de massas, mas antes, poderão constituir extaordinárias vias de conhecimento e exame dessa mesma sociedade" (p. 14). Bela esperança! Temo, porém, que se trate de uma forma mais alta de wishful thinking.

Mas sobretudo me causa estranheza o desdobramento dessa reflexão: "Nessa perspectiva, a produção de 'eventos' e o funcionamento do museu como 'centro cultural' são legítimos e desejáveis apenas para multiplicar e potenciar as funções do museu enquanto museu (...). Noutros termos, aqui... a palavra de ordem seria a integração do museu a outros patamares de ações e funções, além das que the são consubstanciais (...)". Vejo implícito aí um argumento derivado de uma metafísica essencialista, que conceberia uma espécie de museu kantiano, noumênico. Parece-me estranho isso num historiador e com relação a uma instituição social eminentemente histórica, cujas funções são mutáveis e definidas ao sabor das épocas, embora possam perdurar certas linhas de força nessa estruturação.

Todavia, em relação à boa discussão contida no tópico Objeto histórico, documento histórico e do papel que os museus rerpesentam aí (p.8-12), penso que teria sido ainda mais fecundo se o autor tivesse incorporado à sua reflexão as relações dialéticas de oposição e de implicação que asseguram a reversibilidade e a metamorfose das calegorias básicas de monumento/documento, tão brithantemente esclarecidas por excelentes estudiosos da área (Foucault 1969, Le Goff 1984 e 1988, Veyne 1971 etc.). Comentar, porém, a riqueza de questões ai envolvida me levaria a extenso excurso. Salientaria apenas as ambigüidades do museu histórico em suas funções de produção cognitiva. Nesse sentido, o próprio autor apressa-se em reconhecer de modo fortemente crítico as dimensões ideológicas de uma instituição como o Museu Paulista da USP. Com efeito, poucos museus expressam de forma tão retórica o projeto político-ideológico de elites em busca de instituir a sua hegemonia em face da nação; e o seu vínculo de pertença com relação à Universidade de São Paulo tanto pode representar uma via de retificação crítica, como pode desvelar a que ponto esta última instituição seria parte integrante do projeto.

Ainda que recheada de fecunda discussão sobre a exposição museológica como convenção, a falsa alternativa "objetos versus idéias", e a exposição como linguagem ou discurso, penso que a terceira parte deste ensaio teria a ganhar na sua força analítica se tivesse insistido um pouco mais no papel das imagens sobretudo na cultura contemporânea e na dimensão do imaginário, que esse questionamento implica inelutavelmente (ver, por exemplo, - clássico estudo de Fulchignoni 1969; também Jeudy 1986 e mais especialmente Debray 19921.

No final de seu curto e incisivo ensaio sobre "documento/monumento", Le Goff conclui que, a partir da revolução da noção de 
documento, alargado para além dos textos tradicionais e transformado quase sempre em dado, é urgente a elaboração de "uma nova erudição capaz de transferir este documento/monumento do campo da memória para o da ciência histórica" (1984: 104). Vejo aí uma bela convergência com a proposição contida no título e na argumentação do ensaio objeto deste comentário, só que, no caso, a direção aponta no rumo da construção cognitiva como função precípua do museu histórico. Numa recomposição de suas próprias palavras: "Não sendo a História um conjunto a priori de noções, afirmações e informações - mas uma leitura em que ela mesma institui, em última instância, aquilo que pretende tornar inteligível -, ensinar História só pode ser, obrigatoriamente, ensinar a fazer História...' Por isso, a diretriz de um museu histórico seria tansformar-se num recurso para fazer História com objetos e ensinar como se faz História com os objetos. (...) Se o Teatro da Memória é um espaço de espetáculo que evoca, celebra e encultura, o Laboratório da História é o espaço de trabalho sobre a memória, em que ela é tratada, não como um objetivo, mas como objeto de conhecimento". E o autor conclui exprimindo a confiança de que o museu histórico talvez já esteja maduro para explorar com competência e por vocação (ainda que não atualizada): a transformação dos objetos em documentos históricos. Reitero o que antes afirmei no início: é uma generosa sugestão. De todo modo, nessa como em outras matérias pode-se consultar Tirésias que, por óbvias razões, não freqüentava museus, mas sabia de muitas coisas, sobretudo em relação ao futuro. 